Thorax (1968), 23, 19.

\title{
Arterial hypoxaemia \\ A side-effect of intravenous isoprenaline used after cardiac surgery
}

\author{
R. M. M . FORDHAM AND LEON RESNEKOV \\ From the Department of Anaesthetics, St. Thomas' Hospital, London, S.E.1, and \\ the Institute of Cardiology, National Heart Hospital, London, W.I
}

Intravenous administration of isoprenaline following cardiac surgery has been shown to cause an increase in existing arterial hypoxaemia. This is considered to be due to an increase in venous admixture following interference with the normal compensatory mechanism which in the presence of alveolar hypoxia tends to maintain normal ventilation-perfusion relationships.

The occurrence of arterial hypoxaemia following cardiopulmonary bypass has been demonstrated by many workers despite the fact that the postoperative course is uncomplicated (Geha, Sessler, and Kirklin, 1966; Fordham, 1965; HedleyWhyte, Corning, Laver, Austen, and Bendixen, 1965 ; McClenahan, Young, and Sykes, 1965). An increase in pulmonary venous admixture secondary to alveolar collapse has been suggested as the mechanism, although the precise aetiology remains uncertain. The presence of non-ventilated alveoli is shown by a high venous admixture even when $100 \%$ oxygen is inhaled.

Intravenous isopropylnoradrenaline sulphate (isoprenaline) is a drug commonly used after cardiac surgery in the treatment of low output states and heart-block. Whilst investigating the cardiovascular effects of isoprenaline after cardiac surgery it was noted that arterial oxygen saturation decreased during infusion of the drug. This paper describes the finding and attempts to explain its mechanism.

\section{METHODS}

Seven patients aged 39 to 56 years who had undergone homograft replacement of the aortic valve under total cardiopulmonary bypass were studied 16 to 20 hours post-operatively. Three patients had aortic valve disease with stenosis and regurgitation, one had aortic regurgitation, one had aortic stenosis, and one had mixed aortic valve disease with, in addition, mitral stenosis ; one patient had aortic valve stenosis with mitral stenosis and regurgitation. Mitral valve disease was corrected surgically at the time of homograft replacement of the aortic valve in the two patients with associated mitral valve disease. The post-operative state of all the patients studied was satisfactory and no patient required therapy other than routine post-operative care. The position of the patients was constant during the study, with a head-up tilt of $15^{\circ}$ to $30^{\circ}$, and all patients were breathing air spontaneously.

Pulmonary arterial and left atrial pressures were measured through catheters inserted towards the end of the operation, using a pressure transducer (Statham P.23G) and an oscillographic recorder (Sanborn Model 296). Two- or three-minute expired air collections were made using a mouthpiece, noseclip, and one-way valve, the total dead space of the apparatus being $60 \mathrm{ml}$. During the collections of expired air mixed venous blood was drawn into siliconized, heparinized syringes via the pulmonary arterial catheter, and arterial blood through a catheter (T.F.10) inserted into the brachial artery by the Seldinger technique and advanced into the ascending aorta.

Observations were made before beginning the infusion of isoprenaline and were repeated at each dosage level. Isoprenaline was infused intravenously using a constant rate injection apparatus ${ }^{1}$ for 10 minutes before and during each study.

Blood samples were analysed for oxygen saturation using a haemo-reflector (Brinkman and Zylstra, 1949) and oxygen content was calculated from the percentage saturation and haemoglobin values, a correction being made for dissolved oxygen. This method has been found in this laboratory to agree to within $\pm 2 \%$ when compared with the Van Slyke manometric technique

${ }^{1}$ C. F. Palmer (London) Ltd. 
(Manders and Sillett, personal communication, 1966). Gas samples were analysed using a LloydHaldane gas analysis apparatus, and the gas volume was measured with a calibrated ParkinsonCowan dry gas meter and expressed at S.T.P.D.

Cardiac output was calculated by the direct Fick method; venous admixture by the method of Finley, Lenfant, Haab, Piiper, and Rahn (1960), assuming the pulmonary capillary blood was $97 \%$ saturated; and pulmonary vascular resistance as described by Wood (1958).

\section{RESULTS}

The average overall results for the series are shown in Table I, and the individual results in one patient (C.H.) in Table II. In all patients the administration of isoprenaline was associated with a fall in arterial oxygen saturation and an increase in mixed venous saturation and in pulmonary venous admixture, although in two patients the arterial saturation changes were partially reversed at higher dosage levels (Fig. 1). These changes were associated with a rise in cardiac output and with a fall in the fraction of carbon dioxide in $\stackrel{\vec{\rho}}{+}$ mixed expired air and in pulmonary arterial and? mean left atrial pressures. In two patients nodal $\frac{\overline{ }}{\bar{N}}$ ectopic beats occurred during the infusion of iso- $\frac{\text { ? }}{7}$ prenaline, and this was associated with a fall in $\mathbb{Q}$ cardiac output in both. Pulmonary vascular resist-® ance fell in those patients in whom it was above $-\vec{\circ}$ $2.5 \mathrm{~mm} . \mathrm{Hg} / \mathrm{l} . / \mathrm{min}$. before isoprenaline infusion.Changes in minute ventilation were variable, with $\vec{\omega}$ a small average rise. In individual cases similaro changes in minute ventilation and carbon dioxide $\vec{x}$ excretion were found, and a strong linear relationship was found between percentage changes in minute ventilation and percentage changes in $\vec{\omega}$ carbon dioxide output from control values $(r=0$ $0.989, \mathrm{t}=23 \cdot 1, \mathrm{P}<0 \cdot 001)$. Percentage changes in minute ventilation were generally slightly largerc than percentage changes in carbon dioxide. The proportionate increase in blood flow through the underventilated compartment of the lung during 2 isoprenaline infusion was found to be much largere than the increase through the ventilated compart-o ment when changes in venous admixture wereo recalculated in terms of actual blood flow through?

\section{T A B L E I}

OVERALL RESULTS: MEAN VALUES AND RANGES

\begin{tabular}{|c|c|c|c|c|c|c|c|c|c|c|c|c|c|}
\hline $\begin{array}{c}\text { Dose } \\
\text { ( } \mu \mathrm{g} . / \mathrm{min} .) \\
\text { (No. of } \\
\text { Patients) }\end{array}$ & $\begin{array}{c}\text { M.V. } \\
\text { (1./min.) }\end{array}$ & $\mid \begin{array}{c}\mathrm{CO}_{2} \\
\text { (ml./min.) }\end{array}$ & $\underset{(\%)}{\mathrm{FECO}_{2}}$ & $\begin{array}{l}\mathrm{SaO}_{2} \\
(\%)\end{array}$ & $\underset{(\%)}{\mathrm{CaO}_{2}}$ & $\begin{array}{c}C \bar{v} \mathrm{O}_{2} \\
(\%)\end{array}$ & $\underset{(\%)}{\dot{Q} \mathbf{Q}}$ & $\begin{array}{c}\dot{\mathrm{Q} s} \\
(1 . / \mathrm{min} .)\end{array}$ & $\left|\begin{array}{c}\dot{\mathbf{Q}}-\mathbf{Q} \mathbf{s} \\
\text { (1./min. })\end{array}\right|$ & $\left|\begin{array}{c}\mathrm{CO} \\
(1 . / \mathrm{min} .)\end{array}\right|$ & $\begin{array}{l}\text { M.P.A.P. } \\
\text { (mm. Hg) }\end{array}$ & $\begin{array}{l}\text { M.L.A.P. } \\
(\mathrm{mm} \text {. Hg) }\end{array}$ & $\underset{(\mathrm{mm} . \mathrm{H} . \mathrm{Hg}}{\mathrm{P}}$ \\
\hline $\begin{array}{c}\text { Control } \\
\text { (7) }\end{array}$ & $\begin{array}{c}7.92 \\
6.07- \\
10 \cdot 48\end{array}$ & $\begin{array}{l}207 \\
150- \\
245\end{array}$ & $\begin{array}{l}2 \cdot 65 \\
2 \cdot 34- \\
3 \cdot 30\end{array}$ & $\begin{array}{l}92 \cdot 3 \\
88 \cdot 5- \\
96\end{array}$ & $\begin{array}{l}16 \cdot 5 \\
14 \cdot 7- \\
18 \cdot 5\end{array}$ & $\begin{array}{c}9 \cdot 15 \\
7 \cdot 5- \\
11 \cdot 1\end{array}$ & $\begin{array}{l}10 \\
2- \\
20\end{array}$ & $\begin{array}{l}0.34 \\
0.08- \\
0.86\end{array}$ & $\begin{array}{l}3 \cdot 28 \\
2 \cdot 34 \\
3 \cdot 96\end{array}$ & $\begin{array}{l}3 \cdot 61 \\
2 \cdot 7- \\
4 \cdot 3\end{array}$ & $\begin{array}{l}18 \cdot 0 \\
12 \cdot 5- \\
27\end{array}$ & $\begin{array}{c}8 \cdot 5 \\
3 \cdot 0- \\
11 \cdot 5\end{array}$ & $\begin{array}{l}2 \cdot 81 \\
1 \cdot 5- \\
6 \cdot 4\end{array}$ \\
\hline $\begin{array}{l}0.75 \\
(7)\end{array}$ & $\begin{array}{c}8 \cdot 36 \\
6 \cdot 18- \\
11 \cdot 95\end{array}$ & $\begin{array}{l}214 \\
161- \\
275\end{array}$ & $\begin{array}{l}2 \cdot 61 \\
2 \cdot 20- \\
3 \cdot 32\end{array}$ & $\begin{array}{l}88 \cdot 5 \\
83- \\
95\end{array}$ & $\begin{array}{l}15 \cdot 85 \\
18 \cdot 3- \\
13 \cdot 6\end{array}$ & $\begin{array}{c}9 \cdot 68 \\
11.4- \\
7.8\end{array}$ & $\begin{array}{l}19 \\
5- \\
35\end{array}$ & $\begin{array}{l}0 \cdot 92 \\
0 \cdot 20- \\
2 \cdot 32\end{array}$ & $\begin{array}{l}3 \cdot 80 \\
3 \cdot 01- \\
4 \cdot 73\end{array}$ & $\begin{array}{l}4 \cdot 72 \\
3 \cdot 8- \\
6 \cdot 6\end{array}$ & $\begin{array}{l}17 \cdot 4 \\
13- \\
27 \cdot 5\end{array}$ & $\begin{array}{c}7 \cdot 1 \\
3 \cdot 0- \\
11 \cdot 0\end{array}$ & $\begin{array}{l}2 \cdot 38 \\
1 \cdot 3- \\
5 \cdot 0\end{array}$ \\
\hline Significance & N.S. & N.S. & N.S. & $P<0.01$ & $P<0.01$ & $P<0.001$ & $P<0.01$ & $P<0.05$ & $P<0.01$ & $P<0.001$ & N.S. & $\mathrm{P}<0.05$ & N.S. \\
\hline
\end{tabular}

M.V.=minute volume; $\mathrm{FECO}_{2}=$ fraction of $\mathrm{CO}_{2}$ in expired air; $\mathrm{SaO}_{2}=$ arterial oxygen saturation ; CaO $=$ arterial oxygen content;

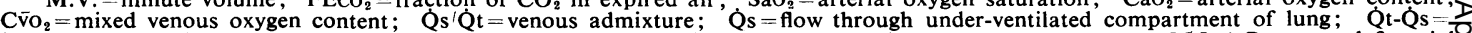
flow through ventilated compartment; $\mathbf{C O}=$ cardiac output; M.P.A.P. = mean pulmonary artery pressure; M.L.A.P. mean left atrial pressure; P.V.R. = pulmonary vascular resistance; N.S. = not significant.

T A B L E I I

RESULTS IN PATIENT C.H.

\begin{tabular}{|c|c|c|c|c|c|c|c|c|c|c|c|c|c|c|}
\hline $\begin{array}{l}\text { Dose } \\
\text { ( } \mu \mathrm{g} . \\
\text { min. })\end{array}$ & $\begin{array}{c}\text { M.V. } \\
(1 . \\
\text { min. })\end{array}$ & $\underset{(\%)}{\mathrm{FECO}_{2}}$ & $\begin{array}{c}\mathrm{CO}_{3} \\
\text { Output } \\
\text { (ml./min.) }\end{array}$ & $\begin{array}{c}\mathrm{PaCO}_{2} \\
\underset{\mathrm{Hg}}{(\mathrm{mm}} .\end{array}$ & $V_{D} V_{T}$ & $\underset{(1 . / \mathrm{min} .)}{\dot{\mathrm{VA}}}$ & $\underset{(\%)}{\mathrm{SaO}_{2}}$ & $\begin{array}{c}\text { Q́s } / \dot{Q} t \\
(\% / \% \\
\text { of } \mathrm{CO})\end{array}$ & $\underset{(1 . / \mathrm{min} .)}{\dot{\text { ss }}}$ & $\begin{array}{c}\dot{Q} \mathrm{t}-\dot{Q} \mathrm{~s} \\
(1 . / \mathrm{min} .)\end{array}$ & $\stackrel{\mathrm{CO}}{(1 . \mathrm{min} .)}$ & $\begin{array}{l}\text { M.P.A.P. } \\
\underset{\mathbf{H g}}{\mathbf{H g m}}\end{array}$ & $\underset{\text { (mg) }}{\text { M.L.A.P. }}$ & $\begin{array}{l}\text { P.V.R. } \\
\text { (mm.Hg } \\
\text { l./min.) }\end{array}$ \\
\hline $\begin{array}{c}\text { Control } \\
0.75 \\
1.00 \\
1.25\end{array}$ & $\begin{array}{l}7 \cdot 28 \\
7 \cdot 40 \\
7 \cdot 38 \\
9 \cdot 05\end{array}$ & $\begin{array}{l}2 \cdot 91 \\
2 \cdot 85 \\
2 \cdot 78 \\
2 \cdot 77\end{array}$ & $\begin{array}{l}212 \\
211 \\
205 \\
251\end{array}$ & $\begin{array}{l}42 \\
42 \\
42 \\
40\end{array}$ & $\begin{array}{l}0.50 \\
0.51 \\
0.52 \\
0.50\end{array}$ & $\begin{array}{l}3 \cdot 64 \\
3.63 \\
3 \cdot 54 \\
4 \cdot 52\end{array}$ & $\begin{array}{l}92 \\
85 \\
86 \cdot 5 \\
87 \cdot 5\end{array}$ & $\begin{array}{l}10 \\
25 \\
20 \\
19\end{array}$ & $\begin{array}{l}0.37 \\
1.18 \\
0.80 \\
0.91\end{array}$ & $\begin{array}{l}3 \cdot 34 \\
3 \cdot 54 \\
3 \cdot 2.2 \\
3 \cdot 89\end{array}$ & $\begin{array}{l}3 \cdot 71 \\
4 \cdot 72 \\
4 \cdot 02 \\
4 \cdot 80\end{array}$ & $\begin{array}{l}16 \\
16 \\
13 \cdot 5 \\
13\end{array}$ & $\begin{array}{l}9 \\
6 \\
4 \cdot 5 \\
5\end{array}$ & $\begin{array}{l}1 \cdot 9 \\
2 \cdot 1 \\
2 \cdot 2 \\
1 \cdot 7\end{array}$ \\
\hline
\end{tabular}

These results are not typical of the whole series. A fall in cardiac output occurred at doses of 1.0 and $1.25 \mu \mathrm{g}$. $/ \mathrm{min}$. following the appearance of nodal ectopic beats, and he was the only patient in whom venous admixture fell again at higher isoprenaline dosage levels. $\sigma$ $\mathrm{PaCO}_{2}=$ partial pressure of $\mathrm{CO}_{2}$ in arterial blood; $\mathrm{VD} / \mathrm{VT}=$ ratio of physiological dead space to tidal volume, including apparatus dead space, $\mathrm{PaCO}_{2}=$ partial pressure of $\mathrm{CO}_{2}$ in arterial blood; $\mathrm{VD} / \mathrm{VT}=\mathrm{ratio}$
$\mathrm{VA}=$ alveolar ventilation. Other abbreviations as in Table I. 
these areas $(+171 \%$ through the underventilated compartment as compared to $+16 \%$ through the ventilated compartment at a dose of $0.75 \mu \mathrm{g}$. $/ \mathrm{min}$. (Fig. 2) ). Changes in venous admixture resulting from isoprenaline infusion were generally found to be directly related to the venous admixture before infusion (Fig. 3).

\section{DISCUSSION}

The possible causes of the decreased arterial saturation noted in this series of patients are (1) a rise in the partial pressure of carbon dioxide in the alveoli $\left(\mathrm{PACO}_{2}\right)$; (2) an increasing diffusion defect; and (3) changing relationships in alveolar ventilation and perfusion.

alveolar PCO ${ }_{2}$ Changes The calculation of the venous admixture demands a knowledge of the oxygen content of pulmonary capillary blood. The

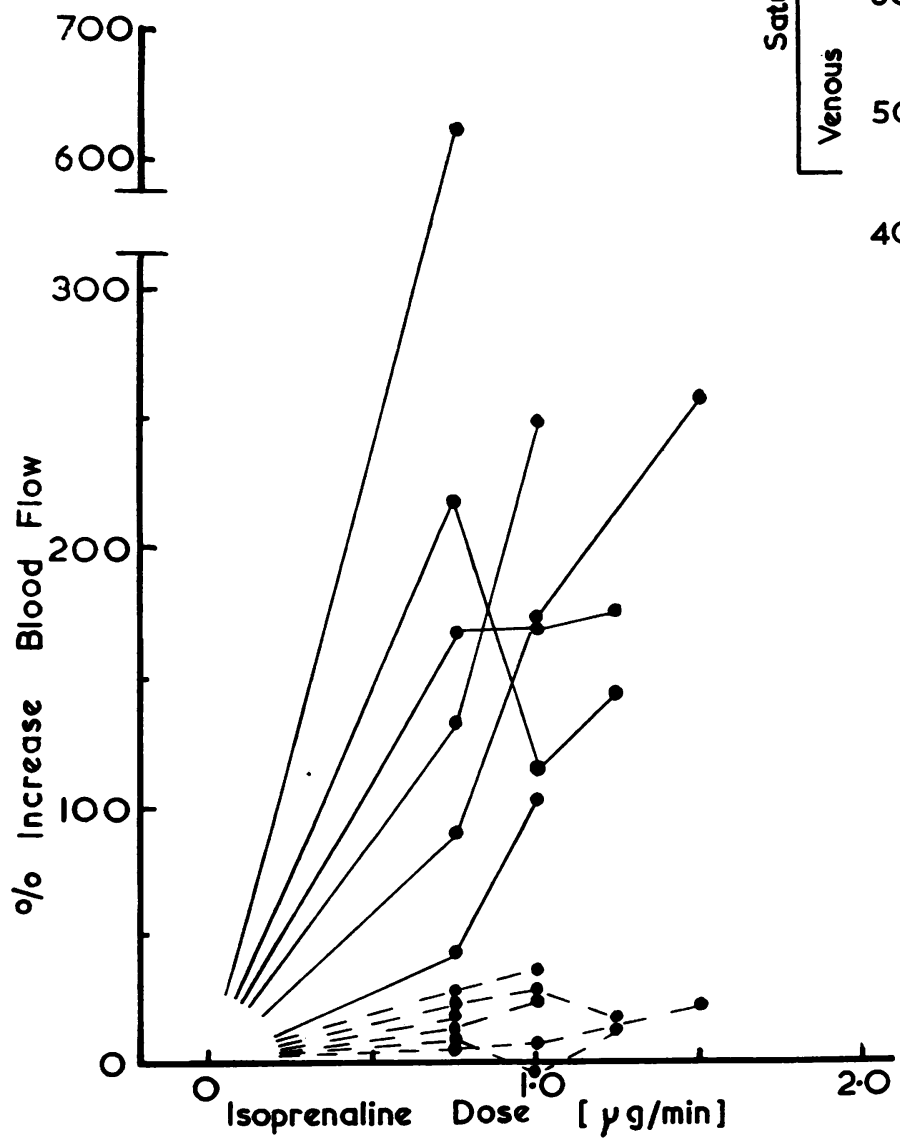

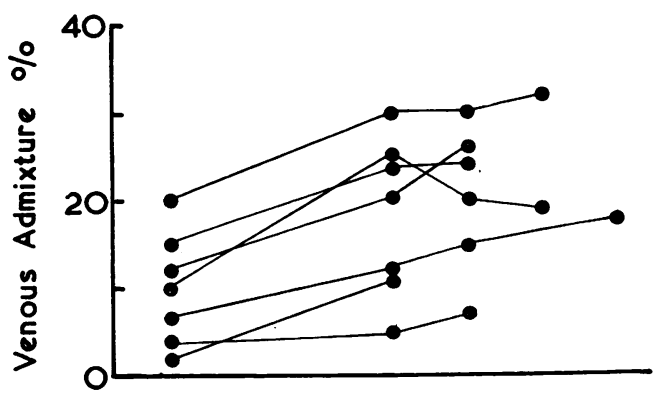
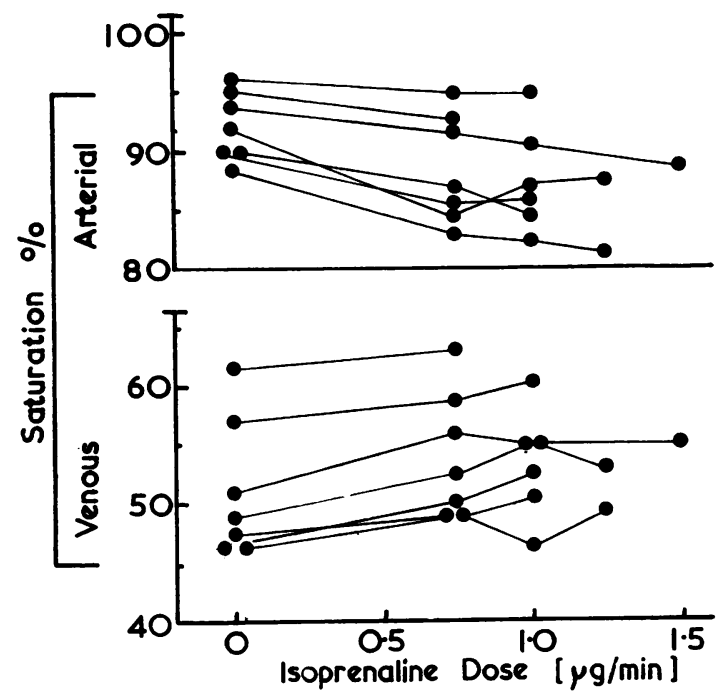

FIG. 1. Arterial and mixed venous oxygen saturations and venous admixture values plotted against the isoprenaline dose.
FIG. 2. Percentage changes in blood flow through the underventilated ( $\bullet-\bullet)$ and ventilated $(\bullet---\bullet)$ compartments of the lung plotted against the isoprenaline dcse. 


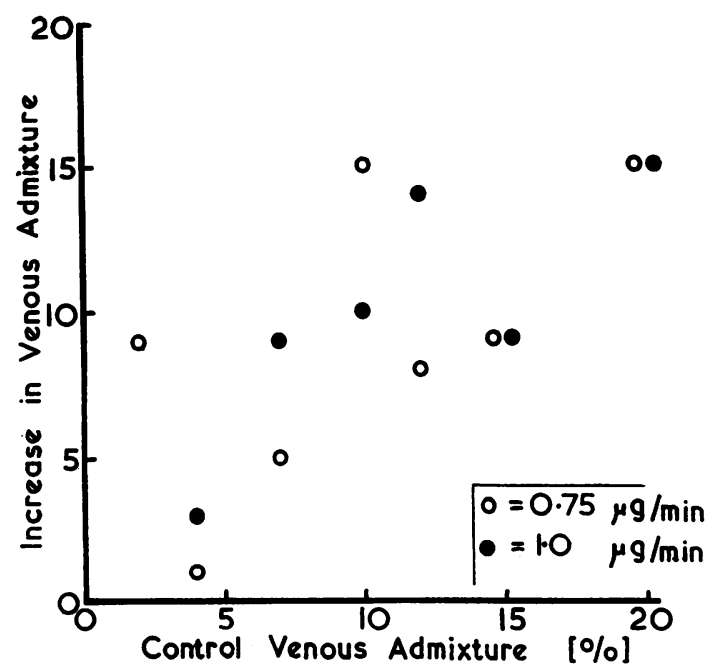

FIG. 3. Changes in venous admixture resulting from isoprenaline infusion plotted against venous admixture before infusion. Isoprenaline dosage $=0.75$ and $1.0 \mu \mathrm{g} . / \mathrm{min}$.

alveolar $\mathrm{Po}_{2}$ is influenced by the alveolar $\mathrm{PCO}_{2}$ and may be calculated from the alveolar air equation (Comroe, Forster, DuBois, Briscoe, and Carlson, 1962). Assuming that equilibration occurs between alveolar air and pulmonary capillary blood, the oxygen content of the capillary blood can be calculated from the values for haemoglobin and alveolar $\mathrm{Po}_{2}$. In this series assumed values of $40 \mathrm{~mm}$. $\mathrm{Hg}$ for the alveolar $\mathrm{PCO}_{2}$ and $97 \%$ for the oxygen saturation of pulmonary capillary blood were used in calculating venous admixture. The arterial $\mathrm{PCO}_{2}$ was measured in only one patient, so that changes in the oxygenation of the arterial blood may have been influenced by changes in alveolar $\mathrm{PCO}_{2}$. Alveolar $\mathrm{PcO}_{2}$ depends, however, on alveolar ventilation, carbon dioxide output, and barometric pressure. The close direct relationship between changes in minute ventilation and changes in carbon dioxide output found during isoprenaline administration indicate that large changes in alveolar $\mathrm{Pco}_{2}$ were unlikely, and that a small fall probably occurred in most instances. Also, it can be shown that, provided no change occurs in the ratio of physiological dead space to tidal volume $\left(\mathrm{V}_{\mathrm{D}} / \mathrm{V}_{\mathrm{T}}\right)$, the alveolar $\mathrm{PCO}_{2}$ is directly proportional to the $\mathrm{PCO}_{2}$ in mixed expired air $\left.\mathrm{PeCO}_{2}\right) ; \mathrm{PeCO}_{2}$ tended to fall slightly in all our patients. In patient C.H. (Table II) a fall occurred in both arterial $\mathrm{PCO}_{2}$ and in $\mathrm{PeCO}_{2}$ and the ratio $\mathrm{V}_{\mathrm{D}} / \mathrm{V}_{\mathrm{T}}$ showed only minimal changes. It appears, therefore, that a small fall in alveolar $\mathrm{PCO}_{2}$ probably occurred in our patients during the infusion, and that a significant rise in alveolar $\mathrm{PCO}_{2}$ was unlikely. This finding is confirmed by Eckstein and Hamilton (1959), who found a fall in endexpiratory $\mathrm{PCO}_{2}$ (average fall $5.8 \mathrm{~mm} . \mathrm{Hg}$ ) during the infusion of $5.8 \mu \mathrm{g} . / \mathrm{min}$. isoprenaline. A fall $\stackrel{D}{D}$ in alveolar $\mathrm{PCO}_{2}$ during infusion would lead to an underestimation of venous admixture changes in $\vec{\circ}$ our series. The approximate error in the estimated venous admixture caused by large variations in $\vec{\omega}$ alveolar $\mathrm{PCO}_{2}$ from our assumed value of $40 \mathrm{~mm}$. $\mathrm{Hg}$ can be calculated. Before isoprenaline in- $\vec{x}$ fusion, variations in alveolar $\mathrm{PCO}_{2}$ from this figure, $\underset{\mathrm{\omega}}{\mathrm{N}}$ but within the range 20 to $50 \mathrm{~mm}$. $\mathrm{Hg}$, may have caused an error of up to $2 \%$ in absolute values for $\overrightarrow{\vec{\theta}}$ venous admixture. Alterations in alveolar $\mathrm{Pco}_{2}$ 을 during isoprenaline infusion of up to $10 \mathrm{~mm}$. $\mathrm{Hg}$ from control values (within the range 20 to $50 \mathrm{c}$ $\mathrm{mm}$. $\mathrm{Hg}$ ) may have caused an error in estimated venous admixture changes of up to $2 \%$. These errors are small compared with many of the changes actually observed, and the alveolar $\mathrm{PcO}_{2} \overrightarrow{\mathscr{\theta}}$ limits chosen are greater than those found on the $\infty$ first post-operative day following open cardiac surgery in patients who are progressing satisfactorily (Fordham, 1965; McClenahan et al., 1965).

It appears, therefore, that changes in arterial oxygenation due to changes in alveolar $\mathrm{PCO}_{2}$ were probably small in the present series and would lead to underestimation of venous admixture changes.

DIFFUSION DEFECT The presence of a diffusion defect in the lungs after open cardiac surgery has been considered minimal (Geha et al., 1966; Fordham, 1965; McClenahan et al., 1965; Hedley-Whyte et al., 1965) and there is no evidence to suggest that this type of defect is increased by infusion of isoprenaline.

VENTILATION-PERFUSION RELATIONSHIPS Increas- 은 ing arterial hypoxaemia due to changes in the $\frac{D}{0}$ ventilation-perfusion relationships can be produced either by an increase in the number of $N$ alveoli which are under-ventilated or non-ventilated, or by an increase in blood flow through $\mathcal{N}$ alveoli which are already under-ventilated. The $\omega$ mechanism of arterial hypoxaemia following open cardiac surgery is considered to be mainly alveolar 0 collapse whilst blood flow through the collapsed $\mathbb{D}$ alveoli is relatively well maintained. Whether iso- $?$ prenaline increases this alveolar collapse is un- $\frac{T}{7}$ known, although it seems unlikely in view of the bronchodilator action of the drug.

That alveolar hypoxia causes pulmonary vaso- $\stackrel{\mathbb{D}}{2}$ constriction is well established in dogs (Lloyd, 1966) and probably occurs in man (Fishman, 
1961 ; Lopez-Majano, Wagner, Twining, Tow, and Chernick, 1966). A compensatory train of events occurs to minimize arterial hypoxaemia resulting from alveolar hypoxia. Alveolar collapse leads to local alveolar hypoxia and the resulting vasoconstriction leads to a fall in the perfusion of collapsed alveoli. Interference with this mechanism is consistent with the findings in this series. Dilatation of previously constricted pulmonary vessels would result in increased venous admixture (Fig. 1), and increases in cardiac output would be preferentially distributed to the under-ventilated compartment of the lung (Fig. 2). Also, the more widespread the disturbance in the ventilation-perfusion relationships, the greater will be the effect of interfering with any compensatory mechanism which may be operating (Fig. 3). Further evidence in support of this hypothesis is the reduction in pulmonary vascular resistance found in some cases in the present series, and this is confirmed in man by other workers (Dodge, Lord, and Sandler, 1960 ; Lee, Roveti, and Ross, 1963 ; Williams, White, and Behnke, 1963). Aviado and Schmidt (1957) and Hebb and Konzett (1949) have also shown that isoprenaline produces pulmonary vasodilatation in the isolated, perfused dog lung.

We should like to thank Mr. D. N. Ross for allowing us to study his patients, and Dr. S. J. G. Semple for reading the manuscript. This work was aided by a grant from the St. Thomas' Hospital Endowment Fund.

\section{REFERENCES}

Aviado, D. M., and Schmidt, C. F. (1957). Effect of sympathomimetic drugs on pulmonary circulation: with special reference to a new pulmonary vasodilator. J. Pharmacol. exp. Ther., 120, 512.

Brinkman, R., and Zylstra, W. G. (1949). Determination and continuous registration of the percentage oxygen saturation in clinical conditions. Arch. Chir. Neerl., 1, 177.

Comroe, J. H., Forster, R. E., DuBois, A. B., Briscoe, W. A., and Carlson, E. (1962). The Lung, 2nd ed., p. 339. Year Book Medical Publishers, Chicago.

Dodge, H. T., Lord, J. D., and Sandler, H. (1960). Cardiovascular effects of isoproterenol in normal subjects and subjects with congestive heart failure. Amer. Heart J., 60, 94.

Eckstein, J. W., and Hamilton, W. K. (1959). Effects of isoproterenol on peripheral venous tone and transmural right atrial pressure in man. J. clin. Invest., 38, 342 .

Finley, T. N., Lenfant, C., Haab, P., Piiper, J., and Rahn, H. (1960) Venous admixture in the pulmonary circulation of anesthetized dogs. J. appl. Physiol., 15, 418.

Fishman, A. P. (1961). Respiratory gases in the regulation of the pulmonary circulation. Physiol. Rev., 41, 214.

Fordham, R. M. M. (1965). Hypoxaemia after aortic valve surgery under cardiopulmonary bypass. Thorax, $20,505$.

Geha, A. S., Sessler, A. D., and Kirklin, J. W. (1966). Alveolar-arterial oxygen gradients after open intracardiac surgery. $J$. thorac cardiovasc. Surg., 51, 609.

Hebb, C. O., and Konzett, H. (1949). Vaso- and bronchodilator effects of N-isopropyl-norepinephrine in isolated perfused dog lungs. J. Pharmacol. exp. Ther., 96, 228.

Hedley-Whyte, J., Corning, H., Laver, M. B., Austen, W. G., and Bendixen, H. H. (1965). Pulmonary ventilation-perfusion relations after heart valve replacement or repair in man. J. clin. Invest., 44, 406 .

Lee, T. D., Roveti, G. C., and Ross, R. S. (1963). The hemodynamic effects of isoproterenol on pulmonary hypertension in man. Amer. Heart $J ., 65,361$.

Lloyd, T. C., Jr. (1966). Influence of blood $\mathrm{pH}$ on hypoxic pulmonary vasoconstriction. J. appl. Physiol., 21, 358.

Lopez-Majano, V., Wagner, H. N., Twining, R. H., Tow, D. E., and Chernick, V. (1966). Effect of regional hypoxia on the distribution of pulmonary blood flow in man. Circulat. Res., 18, 550.

McClenahan, J. B., Young, W. E., and Sykes, M. K. (1965). Respiratory changes after open-heart surgery. Thorax, $20,545$.

Williams, J. F., White, D. H., and Behnke, R. H. (1963). Changes in pulmonary hemodynamics produced by isoproterenol infusion in emphysematous patients. Circulation, 28, 396.

Wood, P. (1958). Pulmonary hypertension with special reference to the vasoconstrictive factor. Brit. Heart J., $20,557$. 